\title{
Nebulized Mannitol, Particle Distribution, and Cough in Idiopathic Pulmonary Fibrosis
}

\author{
Pooja M Kanth MD MPH, Caesar Alaienia PharmD BCPS BCCCP, and \\ Gerald C Smaldone MD PhD
}

\begin{abstract}
BACKGROUND: Inhaled interferon, a potential treatment for idiopathic pulmonary fibrosis, must be formulated with mannitol, which can cause bronchospasm and cough. Coughing during drug inhalation can be affected by many factors, but some factors are fixed by the needs of the formulation and inflammatory disease in the airways. A component of the cough response may be related to sites of deposition, particularly upper and central airways. If deposition sites are important, then manipulating the particle distribution of the aerosol may mitigate coughing. To design a therapeutic formulation and delivery system for formulations that contain mannitol, we tested the effect of particle distribution on cough during mannitol inhalation in volunteers with idiopathic pulmonary fibrosis. METHODS: A solution of mannitol was formulated to match requirements for future interferon formulations $(40 \mathrm{mg} / \mathrm{mL}, 220 \mathrm{mOsm} / \mathrm{L})$. Mannitol aerosols were generated by using different nebulizers providing particle distributions that were expected to vary upper airway deposition. The nebulizer fill volume was adjusted to correct for differences in nebulizer efficiency with a target inhaled mass of $20 \mathrm{mg}$. Particle distributions were measured by cascade impaction (mass median aerodynamic diameters, 1.2 and $6.5 \mu \mathrm{m}$ ). Seven subjects with idiopathic pulmonary fibrosis participated in the study. To maximize deposition, the subjects were trained to inhale slowly and deeply (6 $\mathrm{s}$ inspiration). Spirometry was measured before and after inhalation. The study was carried out on separate days (day 1: $1.2 \mu \mathrm{m}$; day 2: $6.5 \mu \mathrm{m}$ ), and the pattern of coughing was observed. RESULTS: Coughing was often spontaneous and provoked by spirometry. When inhaling the 1.2- $\mu \mathrm{m}$ distribution, no subject coughed during inhalation. Six of the seven subjects coughed when inhaling the $6.5-\mu \mathrm{m}$ particles. Spirometry was unaffected. CONCLUSIONS: In subjects with idiopathic pulmonary fibrosis, nebulized mannitol can cause coughing. Modifying the aerosol distribution prevents coughing during mannitol inhalation. Mannitol aerosols can be inhaled safely without bronchospasm. These data serve to inform future formulation and/or device combinations for planned interferon therapy. Key words: formulation; deposition; human; lung; breathing; particle distribution. [Respir Care 2018;63(11):1407-1412. (C) 2018 Daedalus Enterprises]
\end{abstract}

\section{Introduction}

Cough frequently occurs during inhalation of aerosolized drugs. When persistent, coughing can interfere with

Drs Kanth and Smaldone are affiliated with the Pulmonary, Critical Care and Sleep Division, Department of Medicine, Health Sciences Center, Stony Brook, New York. Dr Alaienia is affiliated with the School of Pharmacy and Pharmaceutical Sciences, Stony Brook, New York.

Stony Brook University and New York University jointly hold patents, which have been licensed to InspiRx, for using inhaled interferon to treat drug delivery and affect sites and the quantity of deposition $^{1}$ and can limit patient adherence, which results in suboptimal therapy. Many factors potentially contribute to

\footnotetext{
pulmonary disease. Dr Smaldone discloses a relationship with InspiRx. Drs Kanth and Alaienia have disclosed no conflicts of interest.

Correspondence: Gerald C Smaldone MD PhD, Pulmonary, Critical Care and Sleep Division, Department of Medicine, Health Sciences Center T-17, 040, 100 Nicholls Road, Stony Brook, NY 11794-8172. E-mail: gerald.smaldone@stonybrook.edu.
}

DOI: $10.4187 /$ respcare.06153 
coughing, including underlying lung disease, the active drug, formulation components, osmolarity, $\mathrm{pH}$, particle concentration in the gas phase of the aerosol, and sites of deposition. $^{2-4}$

Patients with idiopathic pulmonary fibrosis (IPF) frequently mention a cough, and it is often the presenting symptom of the disease. As a potential therapy for IPF, Diaz et $\mathrm{al}^{5}$ studied the use of inhaled interferon gamma, delivered by the I-neb adaptive aerosol delivery system (Philips Respironics, Parsippany, New Jersey), in 10 subjects with IPF. All the volunteers were tolerant of the drug and continued treatment for at least 2 years; however, during therapy, cough during inhalation was noted in 7 subjects. ${ }^{5}$ Although the sum total of factors that cause cough in any given individual is changeable and complex, analysis of that study revealed several identifiable variables that may have affected cough during the actual delivery of the drug. ${ }^{5}$

First, the formulation (Actimmune, Horizon Pharma, Lake Forest, Illinois), originally cleared for parenteral delivery by subcutaneous injection, requires the presence of mannitol $(40 \mathrm{mg} / \mathrm{mL})$ to ensure stability. Therefore, the subjects in the study by Diaz et $\mathrm{a}^{5}$ inhaled approximately $20 \mathrm{mg}$ of mannitol (the volume of the vial was $0.5 \mathrm{~mL}$ ). Mannitol, in dry powder form, has been cleared by the FDA as a bronchoprovocating agent in asthma and as a tussive-stimulating agent to promote airway clearance in cystic fibrosis. Second, Diaz et $\mathrm{al}^{5}$ reported that, on average, $12.6 \%$ of the deposited particles were located in the upper airways, sites of irritant receptors..$^{2-4}$ These observations indicated that, among other potential causes, deposition of mannitol in the upper airways might have significantly contributed to coughing during inhalation.

To further develop interferon gamma for therapy of IPF and other lung diseases, the drug needs to be reformulated specifically for inhalation. This affords the opportunity to modify the product to reduce the potential for induced cough. Mannitol is necessary for stability, and it cannot be removed. However, formulations of inhaled medications are often linked to the delivery system, that is, the drug is connected to a specific device designed to control particle delivery and deposition. Thus, a new interferon gamma drug and device combination modified to deliver an aerosol with a particle distribution designed to minimize cough, the only reported adverse effect in the study of Diaz et al, 5 is possible. To the extent that mannitol and its pattern of deposition contributed to the observations of Diaz et al, ${ }^{5}$ modifications to the aerosol delivery system may reduce the tendency of the interferon formulation to cause coughing during inhalation. Therefore, the purpose of the present study was to define the behavior of different aerosols of mannitol in subjects with IPF.

Many factors define coughing during aerosol inhalation, and it is not possible to control all of them. Consequently,

\section{QUICK LOOK}

\section{Current knowledge}

Coughing during aerosol inhalation can limit the effectiveness of inhaled therapy, particularly in diseases associated with airway inflammation, such as idiopathic pulmonary fibrosis. Formulating interferon gamma, a protein with potential as an inhaled therapy for idiopathic pulmonary fibrosis, requires the addition of mannitol for protein stability. Mannitol can cause cough and bronchospasm mediated by deposition at sites of central airway and upper respiratory tract irritant receptors.

\section{What this paper contributes to our knowledge}

In subjects with idiopathic pulmonary fibrosis, coughing during mannitol inhalation was affected by the particle distribution of mannitol aerosols. Modifying the nebulizer to limit the inhaled distribution of mannitol to small particles (mass median aerosol diameter, $1.2 \mu \mathrm{m}$ ) prevented coughing during mannitol inhalation. This observation will facilitate the design of well-tolerated delivery systems suitable for future trials of interferon therapy for this disease.

we studied individuals who acted as their own controls to minimize the effects of confounding variables. First, the nebulizers were studied on the bench to define their particle distributions and were modified to produce aerosols of mannitol with a wide range of particle distributions. The devices were modified to generate 2 aerosols: one composed of small particles, likely to avoid the upper airways, and the other, with more large particles, likely to deposit in the upper airways. Device efficiency was determined by measuring the inhaled mass and, with that data, by adjusting the volume fill of each nebulizer to equalize the quantity of mannitol inhaled. A breathing pattern of slow and deep breathing maximized total deposition. Therefore, separate drug inhalations with each aerosol provided similar doses to the respiratory tract with the primary difference being the sites of particle deposition.

It was our goal to deposit interferon aerosols (that contained mannitol) in the distal airways and alveoli by duplicating the data for the deep lung (the site of disease in IPF) from the study of Diaz et al. ${ }^{5}$ In spite of the reported mass median aerosol diameters in that paper, some of the particles in the paper by Diaz et $\mathrm{al}^{5}$ deposited in the upper airways, which possibly contributed to the coughing reported in that study. In the present study, we attempted to remove those particles from the aerosol and test the hypothesis that coughing would be reduced, which thus preserves alveolar delivery and reduces induced cough during 
therapy. The components of the polydisperse distributions in these aerosols are not well described by the mass median aerosol diameters alone. We related deposition to the entire measured distributions, which included different populations of larger particles that can deposit in central airways. Before this study, the relationship to coughing and these particles was not known.

The study was performed on 2 widely separate study days, several weeks apart. Two mannitol formulation and device combinations were created, each delivered similar quantities of mannitol but with different particle distributions designed to primarily affect upper airway deposition. On day 1, the subjects inhaled the small-particle distribution, on day 2, they inhaled the large-particle distribution. Coughing associated with each regimen was observed. To assess for possible bronchospasm, spirometry was performed before and after each inhalation.

\section{Methods}

\section{Test Mannitol Formulation}

A solution of mannitol (Osmitrol 20\% Mannitol Injection USP; Baxter Healthcare, Deerfield, Illinois) was prepared in the research pharmacy by mixing $20 \mathrm{~mL}$ Osmitrol with $80 \mathrm{~mL}$ sterile water $(40 \mathrm{mg} / \mathrm{mL}$ mannitol, Baxter Healthcare). This mixture produced an osmolarity of $220 \mathrm{mOsm} / \mathrm{L}$, which closely approximated the osmolarity of the interferon solution of $235 \mathrm{mOsm} / \mathrm{L}$ used by Diaz et al. ${ }^{5}$

\section{Nebulizers}

On the bench, we tested 2 nebulizers by using an in vitro technique commonly used in our laboratory ${ }^{6-8}$ : (1) The Modified AeroTech II (Fig. 1 Biodex Medical Systems, Shirley, New York) is a jet nebulizer filled with $3.5 \mathrm{~mL}$ of the mannitol formulation and runs at a flow of $10 \mathrm{~L} / \mathrm{min}$, the manufacturer's recommended flow; a one-way valve $(22 \mathrm{~F} \times 22 \mathrm{M}$, ref $160603139-000$, INO Therapeutics, Hampton, New Jersey) was added to the aerosol outflow tract to remove particles on the larger side of the aerosol distribution; and (2) Omron U22 (Omron Healthcare, Kyoto, Japan) is a mesh nebulizer filled with $1 \mathrm{~mL}$ of the mannitol formulation.

Nebulizers were run to dryness. A piston pump provided slow and deep breathing from the test nebulizer (tidal volume, $1500 \mathrm{~mL}$; frequency, 5 breaths/min; inspiratory time, $6 \mathrm{~s}$ ), which duplicated the breathing pattern used by Diaz et al. ${ }^{5}$ Technetium- $99 \mathrm{~m}$ was mixed with the mannitol solution to label the aerosol droplets generated by the nebulizer. Low-flow cascade impaction at $2 \mathrm{~L} / \mathrm{min}$ was used to measure particle distributions (Marple 8-stage impactor, ThermoFischer Scientific, Waltham, Massachusetts).

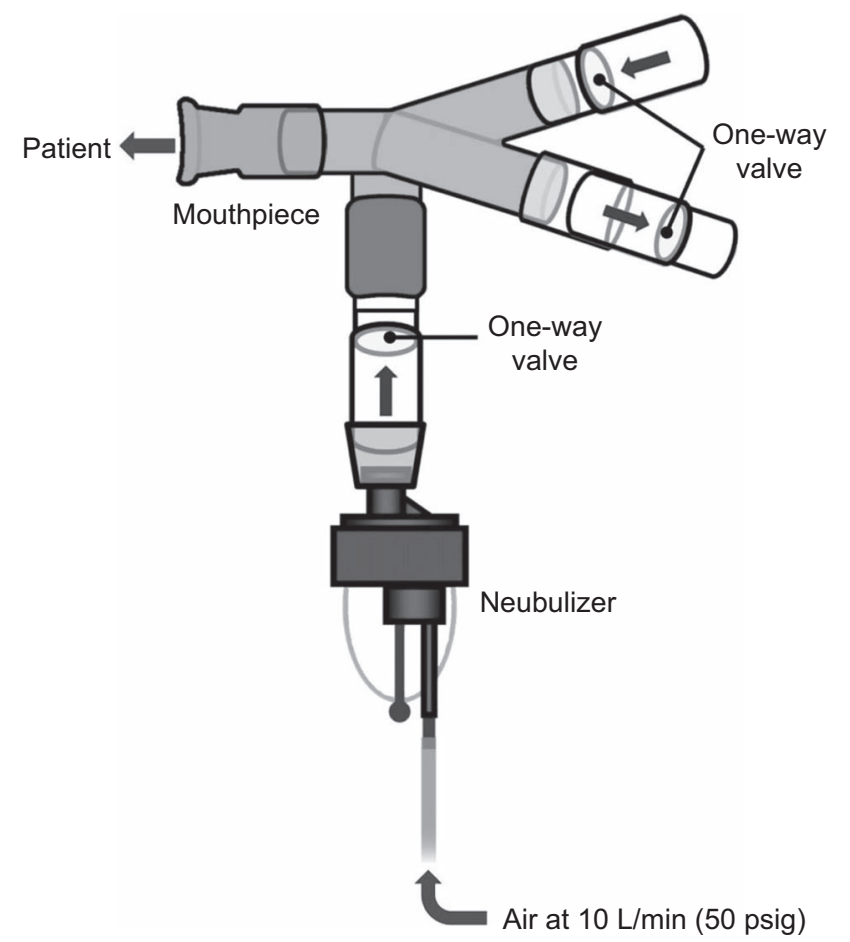

Fig. 1. Modified AeroTech II jet nebulizer. To reduce the number of large particles, a one-way valve was added to the nebulizer outflow track. The other one-way valves in the branched tubing directed inspiratory and expiratory airflow. psig = pounds per square inch gauge.

Table 1. Inhaled Mass Measurements, Nebulizer Fill Volume, and Inhaled Mannitol From Study Devices

\begin{tabular}{lcccc}
\hline \hline Nebulizer & $\begin{array}{c}\text { Inhaled } \\
\text { Mass (\%) }\end{array}$ & $\begin{array}{c}\text { No. } \\
\text { Experiments }\end{array}$ & $\begin{array}{c}\text { Fill } \\
\text { Volume } \\
(\mathrm{mL})\end{array}$ & $\begin{array}{c}\text { Inhaled } \\
\text { Mannitol } \\
(\mathrm{mg})\end{array}$ \\
\hline AeroTech II & $17.7 \pm 1.6$ & 6 & 3.5 & $24.8 \pm 2.3$ \\
Omron & $47.5 \pm 4.8$ & 5 & 1.0 & $19.0 \pm 1.9$ \\
\hline
\end{tabular}

The particles were captured onto filters, and a mass balance was performed to determine the inhaled mass for each nebulizer. The mass balance was determined by measuring radioactivity of various components: cascade impactor, tubing, inhaled mass filter, expired mass filter, and nebulizer. With this information, the nebulizer fill volume was adjusted to correct for different nebulizer efficiencies. The goal for each device was $20 \mathrm{mg}$. The mean data for the final nebulizer configurations are listed in Table 1. Delivered mannitol ranged from 19 to $24 \mathrm{mg}$. The particle distributions of both nebulizers are illustrated in Figure 2. The modified AeroTech II produced particles with a mass median aerosol diameter of $1.2 \mu \mathrm{m}$, whereas the Omron particles were larger, with a mass median aerosol diameter of $6.5 \mu \mathrm{m}$. 


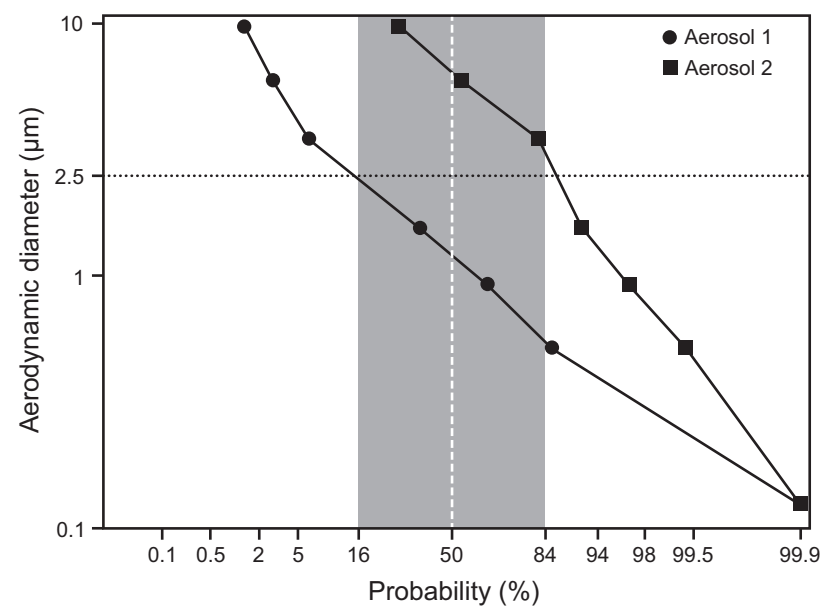

Fig. 2. Aerosol distributions of test aerosols of mannitol made with different nebulizers. Data from cascade impaction plotted as log particle diameter vs probability. Distribution from modified AeroTech Il device (test aerosol no. 1, mass median aerosol diameter, $1.2 \mu \mathrm{m}$ ), Omron device (test aerosol no. 2, mass median aerosol diameter, 6.5 $\mu \mathrm{m})$.

\section{Clinical Protocol}

The study was carried out over 2 days between March and June 2017. Seven subjects with the diagnosis of IPF (diagnosed in our interstitial lung disease clinic) signed an institutional review board approved consent form. As listed in Table 2, all subjects were former smokers, and none were on oxygen. On the first day, the subjects were interviewed and examined. Spirometry was performed by a team member trained in spirometry with flow-volume loops that met American Thoracic Society/European Respiratory Society acceptability and repeatability guidelines before and after inhalation of the test aerosol. The subjects often coughed during spirometry and frequently could not complete 3 maneuvers. Most of the time, however, they were able to perform at least 2 reproducible spirograms. Only attempts during which subjects did not cough during the first second were recorded.

For aerosol inhalation, each volunteer was coached to inhale slowly and deeply from the test nebulizer, with inspiration timed to approximately $6 \mathrm{~s}$ to total lung capacity (similar to I-neb from the study of Diaz et $\mathrm{al}^{5}$ ) and exhalation to residual volume, which resulted in a frequency of approximately 8 breaths $/ \mathrm{min}$. Then, the subject inhaled a full "dose" of mannitol solution, which ran the nebulizer to dryness. Cough events during treatment were recorded. The nebulizers used in the study were all pretested on the bench. Run time for the AeroTech II device was approximately $10 \mathrm{~min}$. Run time for the Omron nebulizer was device-dependent and ranged from 2.5 to $8.5 \mathrm{~min}$. On the first day, all the subjects inhaled from the AeroTech II nebulizer, several weeks later, on the study's second day, they used the Omron device.

\section{Analysis}

Cough data were analyzed qualitatively. Each subject had a unique pattern of coughing triggered by a deep breath or by talking. The subjects were able to suppress coughing to some extent if asked to do a given maneuver such as having a spirogram. In spite of these difficulties, it was relatively easy to do an aerosol inhalation largely because the breathing maneuver used a very slow inhalation. It was not possible to count coughs, but it was possible to note coughing specifically related to aerosol inhalation. If mannitol aerosols provoked coughing, then it was obvious. Spirometry before and after mannitol inhalation was compared by non-parametric paired analysis.

\section{Results}

Results are listed in Table 3. Shown are spirometry data before and after inhalation of the test aerosols, listed as the percent of predicted. Subject 1 was not able to perform spirometry on day 2 due to coordination issues. All data were best efforts because most of the subjects could not complete all 3 spirograms due to coughing. In spite of the clinical evidence of increased airway irritability, with coughing during spirometry, all the subjects were able to perform at least one test. Also listed in Table 3 are the cough data indicated by a "yes" or "no." There was a marked difference in the cough pattern. None of the subjects coughed when inhaling the small particle aerosol, whereas 6 of 7 coughed during inhalation of the large particles.

\section{Discussion}

This study demonstrated that, in subjects with IPF, particle distribution was an important factor that influenced cough during inhalation of mannitol aerosols. It is well known that the aerosol distribution is a key factor in determining regional deposition of inhaled particles, but the importance of the distribution related specifically to cough was not previously well defined. To show this effect, we used 2 devices in the same individual and standardized delivery of the drug. In addition, in spite of increased airway irritability, the subjects with IPF inhaled aerosolized mannitol without bronchospasm. Aerosol no. 1, with a mass median aerosol diameter of $1.2 \mu \mathrm{m}$, did not provoke increased coughing.

The data from the present study may have important implications for future therapeutic trials in this population of patients. Diaz et al $^{5}$ demonstrated that inhaled interferon formulated with mannitol was safe and possibly effective in the test subjects with IPF. However, most of their volunteers coughed during therapy. Diaz et $\mathrm{al}^{5}$ reported that 5 of the 10 coughed. Careful review of their 
Table 2. Subject Information

\begin{tabular}{|c|c|c|c|c|c|c|c|}
\hline \multirow[b]{2}{*}{ Subject No. } & \multirow[b]{2}{*}{ Sex } & \multirow[b]{2}{*}{ Age (y) } & \multicolumn{2}{|c|}{ Smoking History } & \multicolumn{2}{|c|}{ Physical Examination } & \multirow{2}{*}{$\begin{array}{c}\mathrm{D}_{\mathrm{LCO}} \\
(\% \text { predicted })\end{array}$} \\
\hline & & & Year Quit & Pack-Years & $\begin{array}{l}\text { Pulse Oximetry } \\
\text { (room air) }(\%)\end{array}$ & $\begin{array}{c}\text { Frequency } \\
\text { (breaths/min) }\end{array}$ & \\
\hline 1 & $\mathrm{~F}$ & 73 & 1985 & 25 & 97 & 16 & 55 \\
\hline 2 & M & 71 & 1984 & 30 & 98 & 16 & 49 \\
\hline 3 & $\mathrm{~F}$ & 64 & 1990 & 18 & 97 & 14 & 63 \\
\hline 4 & $\mathrm{~F}$ & 70 & 2010 & 25 & 94 & 18 & 76 \\
\hline 5 & M & 76 & 1990 & - & 98 & 16 & 54 \\
\hline 6 & $\mathrm{~F}$ & 73 & 1997 & 35 & 95 & 16 & 44 \\
\hline 7 & F & 78 & 1973 & 35 & 91 & 20 & 31 \\
\hline
\end{tabular}

Table 3. Spirometry Pre and Post Mannitol Inhalation and Cough Observations

\begin{tabular}{|c|c|c|c|c|c|c|c|c|c|c|}
\hline \multirow{3}{*}{ Subject No. } & \multicolumn{5}{|c|}{ Day 1} & \multicolumn{5}{|c|}{ Day 2} \\
\hline & \multicolumn{2}{|c|}{$\begin{array}{c}\text { FVC } \\
\text { (\% predicted) }\end{array}$} & \multicolumn{2}{|c|}{$\begin{array}{c}\mathrm{FEV}_{1} \\
\text { (\% predicted) }\end{array}$} & \multirow{2}{*}{$\begin{array}{l}\text { Cough } \\
\text { Yes or No }\end{array}$} & \multicolumn{2}{|c|}{$\begin{array}{c}\text { FVC } \\
\text { (\% predicted) }\end{array}$} & \multicolumn{2}{|c|}{$\begin{array}{c}\mathrm{FEV}_{1} \\
\text { (\% } \text { predicted) }\end{array}$} & \multirow{2}{*}{$\begin{array}{l}\text { Presence } \\
\text { of Cough }\end{array}$} \\
\hline & Pre & Post & Pre & Post & & Pre & Post & Pre & Post & \\
\hline $1 *$ & 77 & 69 & 79 & 69 & No & ND & ND & ND & ND & Yes \\
\hline 2 & 49 & 51 & 49 & 54 & No & 58 & 55 & 54 & 59 & Yes \\
\hline 3 & 107 & 97 & 106 & 98 & No & 101 & 102 & 116 & 116 & Yes \\
\hline 4 & 53 & 56 & 61 & 61 & No & 71 & 73 & 70 & 72 & No \\
\hline 5 & 52 & 51 & 53 & 53 & No & 54 & 52 & 56 & 53 & Yes \\
\hline 6 & 52 & 51 & 53 & 57 & No & 64 & 59 & 60 & 61 & Yes \\
\hline 7 & 98 & 98 & 113 & 108 & No & 105 & 104 & 113 & 112 & Yes \\
\hline Mean \pm SD & $69.7 \pm 24.4$ & $67.6 \pm 21.4$ & $73.4 \pm 26.6$ & $71.4 \pm 22.4$ & & $75.5 \pm 22.1$ & $74.2 \pm 23.5$ & $78.2 \pm 28.7$ & $78.8 \pm 28.0$ & \\
\hline$P \dagger$ & \multicolumn{2}{|c|}{.53} & \multicolumn{2}{|c|}{.38} & & \multicolumn{2}{|c|}{.34} & \multicolumn{2}{|c|}{.69} & \\
\hline
\end{tabular}

files revealed that, actually, 7 of 10 coughed during inhalation of interferon. In general, the particle distributions from the I-neb mesh device reported from their study were larger than the AeroTech distribution used in the present study. Future formulations of interferon/device combinations containing mannitol will be guided by the AeroTech distribution shown in Figure 2 which did not induce cough.

Our study was limited by several factors. First, we studied a small number of subjects, and we can not conclude that all patients with IPF would behave as these 7 subjects did. However, we had a strong signal for a particle size effect, very similar to that seen by Diaz et $\mathrm{al}^{5}$ in a similar number of individuals. Second, we did not measure actual deposition of aerosol in the lungs of our subjects as Diaz et $\mathrm{al}^{5}$ did. It was possible that some of the smaller particles were exhaled, and the larger particle distribution deposited more mannitol. This possibility was unlikely because we ensured that our subjects inhaled slowly and deeply to maximize deposition of all the particles. Therefore, except for increased upper airway deposition, we expected similar overall deposition in the respiratory tract. Also, it was possible that the other components of Actimmune, such as the interferon itself, used by Diaz et al, ${ }^{5}$ were responsible for the coughing. Data in humans are limited, but Jaffe et $\mathrm{al}^{9}$ used the same formulation as Diaz et $\mathrm{al}^{5}$ in normal volunteers. Jaffe et $\mathrm{al}^{9}$ used an Ultravent nebulizer (Mallinckrodt, St. Louis, Missouri) reported to generate an aerosol with droplets in a size range of $0.2-3 \mu \mathrm{m}$. They treated their subjects over $3 \mathrm{~d}$ and measured drug levels and interferon activity in lung lavage fluid; cough was not reported in their study. ${ }^{9}$

\section{Conclusion}

Modifying the nebulizer resulted in a particle distribution of inhaled mannitol designed to bypass upper and 
central airways. Subjects with IPF inhaled this aerosol without coughing ensuring controlled deposition in the deep lung at sites of fibrosis. This observation is important in formulating aerosols of interferon containing mannitol, which may be effective in treating this serious disease.

\section{ACKNOWLEDGMENTS}

The authors thank Lorraine Morra for assistance with data analysis and preparation of the manuscript.

\section{REFERENCES}

1. Smaldone GC, Itoh H, Swift DL, Wagner HN Jr. Effect of flowlimiting segments and cough on particle deposition and mucociliary clearance in the lung. Am Rev Respir Dis 1979;120(4):747-758.

2. Eschenbacher WL, Boushey HA, Sheppard D. Alteration in osmolarity of inhaled aerosols cause bronchoconstriction and cough, but absence of a permeant anion causes cough alone. Am Rev Respir Dis 1984;129(2):211-215.
3. Lowry RH, Wood AM, Higenbottam TW. Effects of pH and osmolarity on aerosol-induced cough in normal volunteers. Clin Sci (Lond) 1988;74(4):373-376.

4. Sant'Ambrogio G, Widdicombe J. Reflexes from airway rapidly adapting receptors. Respir Physiol 2001;125(1-2):33-45.

5. Diaz KT, Skaria S, Harris K, Solomita M, Lau S, Bauer K, et al. Delivery and safety of inhaled interferon- $\gamma$ in idiopathic pulmonary fibrosis. J Aerosol Med Pulm Drug Deliv 2012;25(2):79-87.

6. Smaldone GC, Fuhrer J, Steigbigel RT, McPeck M. Factors determining pulmonary deposition of aerosolized pentamidine in patients with human immunodeficiency virus infection. Am Rev Respir Dis 1991; 143(4 Pt 1):727-737.

7. Smaldone GC, Perry RJ, Deutsch DG. Characteristics of nebulizers used in the treatment of AIDS-related Pneumocystis carinii pneumonia. J Aerosol Med 1988;1(2):113-126.

8. Sagalla RB, Smaldone GC. Capturing the efficiency of vibrating mesh nebulizers: minimizing upper airway deposition. J Aerosol Med Pulm Drug Deliv 2014;27(5):341-348.

9. Jaffe HA, Buhl R, Mastrangeli A, Holroyd KJ, Saltini C, Czerski $\mathrm{D}$, et al. Organ specific cytokine therapy. Local activation of mononuclear phagocytes by delivery of an aerosol of recombinant interferon-gamma to the human lung. J Clin Invest 1991;88(1): 297-302. 